\title{
Chirally modified gold nanoparticles: nanostructured chiral ligands for catalysis
}

\author{
Markku J. Oila and Ari M.P. Koskinen* \\ Laboratory of Organic Chemistry, Helsinki University of Technology, P.O. Box 6100, \\ FIN-02015 TKK, Finland \\ E-mail: Ari.Koskinen@hut.fi
}

\begin{abstract}
Preparation of novel chiral gold nanoparticles (AuNP) is described. The major advantage of nanoparticles is to combine the easy handling of solid-supported ligands and the efficiency of soluble ligands, as the molecular size of the support approaches the minimum. This is even of industrial interest, because this kind of technology offers a way of avoiding leaching of the catalyst metal in the reaction and separation of the entire catalyst using simple filtration. In this paper, we describe the attachment of a chiral soluble PyOX-ligand on a nano support via simple ligand exchange. As a result, we achieved a core smaller than ever before in experimental chemistry $(1.2 \pm 0.2 \mathrm{~nm})$ and promising enantioselectivity in a preliminary test reaction.
\end{abstract}

Keywords: Nanostructures, gold, chirality, supramolecular chemistry

\section{Introduction}

Applications of gold have been known for at least four centuries, starting from medicinal purposes against various diseases. During the last two decades, gold colloids have gathered a great deal of interest among scientists. ${ }^{1}$ Particularly during this millennium gold colloids have become one of the hottest research areas, mostly due to the discovery of the differing properties of small gold clusters, "nanoparticles", from both organic molecules and bulk metals. It was discovered that a 1-10 nm diameter of the particle would give rise to the observed properties. ${ }^{2}$

In this paper we present a new approach to meet the highly demanding challenges: use of nanostructured particles for catalyst construction. We have demonstrated the feasibility of such an approach by utilizing gold nanoparticles of unprecedented dimensions available for the first time. This approach will pave the way for a new avenue to nearly solution phase catalysis, where the catalyst species is still separable by modern separation techniques such as ultrafiltration.

Solution phase catalysis usually gives virtually diffusion controlled kinetics. The contact between the active catalyst (often a transition metal - organic ligand complex) with the reacting 
partner is tight, and thus the selectivity is highly predictable and tunable. However, downstream processing is hampered by the practically unavoidable leakage of the (catalyst) metal into to the product, which can even completely prohibit the use of such processes, e.g. at a late stage in the synthesis of Active Pharmaceutical Ingredients. Attachment of the solution phase catalyst to a solid support by covalent linkage avoids the leakage problem. A common misconception is that heterogeneous catalysis is desirable, as the catalyst is mechanically easily separable from the reaction mixture by simple filtration or decantation. However, in comparison to homogeneous catalysis, covalent attachment of the catalyst to a solid support typically leads to reduced catalytic activity (especially selectivity), slower reaction rates due to transport phenomena, lack of accessibility of active catalytic sites and leaching of the supported catalyst species. ${ }^{3}$

The first gold particle, prepared in 1981, was the triphenylphosphine-stabilized Schmid's cluster. ${ }^{4}$ When practical synthesis of gold nanoparticles is of concern, the major discovery was the Brust-Schiffrin synthesis in $1994 .^{5}$ It made possible the synthesis of air stable nanoparticles and the use of various solvents through hexanethiolate stabilization of the particles. The synthetic value lay in the possibility to differentiate the size of the gold core by precipitation. New applications have been made using the Brust-Schiffrin - protocol, including water-soluble particles $^{6}$ and other clusters, coated with simply functionalized small molecules (monolayerprotected). ${ }^{7}$ Self-assembly of the layers on gold surface has also been reported, ${ }^{8}$ as well as syntheses giving the opportunity to adjust the core size. ${ }^{9}$ Ionic liquids have also been used in the synthesis of nanoparticles. ${ }^{10}$ To utilize the desired properties of certain metals (e.g. magnetism), also bimetallic cores have been prepared. These bimetallic cores contain an outer layer of gold and the core within of e.g. copper, ${ }^{11}$ cobalt, ${ }^{12}$ palladium ${ }^{13}$ or europium. ${ }^{14}$ The core size has also been reported to affect the reactivity of nanoparticles. ${ }^{15}$ Gold nanoparticles have been used as catalysts in carbon-carbon bond formations, e.g. homocoupling of phenylboronic acid. ${ }^{16}$ Applications on drug discovery are also reported. ${ }^{17}$

To our knowledge, there have been very few reports on chiral gold nanoparticles up to date. ${ }^{18}$ We now report a new chiral nanoligand with a gold core smaller than ever before in experimental chemistry. Since the dimensions of the gold core of our novel particle match those calculated by Johansson et al., ${ }^{19}$ it is suggestive that we have formed a 32 -atom gold cluster, resembling a fullerene structure.

\section{Results and Discussion}

Our approach to the novel nanoparticle was based on ligand exchange. We prepared the hexanethiolate-passivated particles using the Brust-Schiffrin method. ${ }^{5}$ The Brust-Schiffrinparticles 1 (Scheme 1) were dissolved in toluene and the novel thiol containing PyOX-ligand, ${ }^{20}$ was added to the solution in an equimolar ratio. After 25 days, the thermodynamic equilibrium was reached, and the particles were isolated by precipitation with ethanol. Earlier than this could no particles be precipitated this way (at 20 days), probably due to the existence of larger (and 
more soluble) particles (e.g. 1, see Figure 2). We have firstly used elemental analysis as an accurate method to determine the composition of our nanoparticle. The $\mathrm{CHN}$-analysis also gives the ratios between different ligands and gold atoms. These ratios, as well as the character of different atoms and the surface composition, were further explored by ESCA analysis. TEM imaging was used to determine the physical size and the size distribution of the gold core and, in combination with the other techniques, the stoichiometry of the entire cluster. Additionally, the ESCA analysis revealed that all ligands were located on the surface of the cluster, as calculated from the CHN-composition and as also concluded by Johansson et al. ${ }^{19}$

The novel PyOX ligand, used to replace the hexanethiolate groups in the cluster, was synthesized in our laboratory exclusively for this purpose. ${ }^{20}$ Our ligand forms a chiral overlap over the hexanethiolate groups in a suitable way so that the ligand is of the perfect dimension to attach on the gold surface in a 1:1 ratio with the achiral hexanethiolate groups and give the steering chiral information for the entire nano cluster. A larger gold core would lead to more space between the groups and the organized structure would be lost.

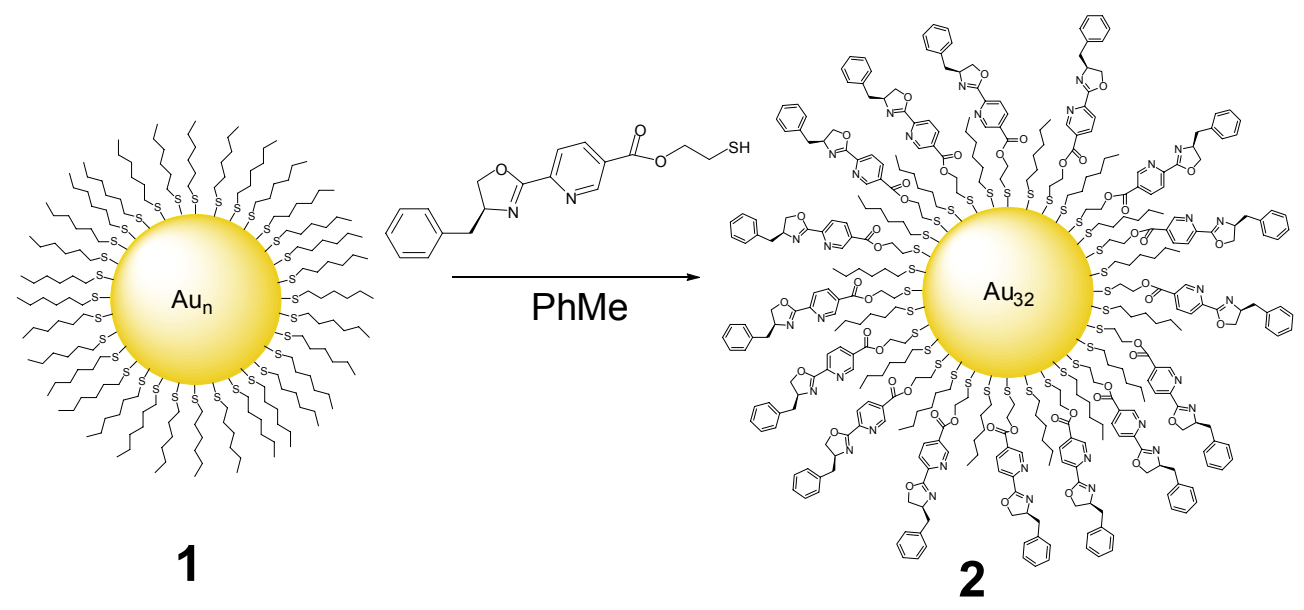

Scheme 1. Synthesis of the novel particle $\mathbf{2}$ and elemental fractions of $\mathbf{1}$ and $\mathbf{2}$.

Elemental analysis data: compound 1: C $26.45 \mathrm{H} 4.43 \mathrm{~N} \mathrm{0}$; compound 2: C $40.76 \mathrm{H} 3.58 \mathrm{~N}$ 3.87 .

From the increased percentage of nitrogen and carbon on $\mathrm{CHN}$-analysis, a total ratio of 1:1 between the PyOX-ligand and the hexanethiolate group was observed (Scheme 1). Since the gold and sulphur ratio also could be calculated equimolar from the CHN-data on $1,{ }^{21}$ the overall atomic ratio of $\mathrm{Au}: \mathrm{S}: \mathrm{N}=1: 1: 1$, indicating that all gold atoms are attached to sulphur on the surface in ligands $\mathbf{1}$ and $\mathbf{2}^{21}$ and the gold core would thus be hollow. This observation is in accordance with the results of the ESCA analysis. The size distribution of our particles was determined using TEM microscopy. The particles were quite uniformly sized with a distribution maximum at $1.2 \pm 0.2 \mathrm{~nm}$ (Figures 1 and 2). To our knowledge, particles of this size have never 
been experimentally synthesized. Both water soluble, ${ }^{6}$ and achiral catalytially active ${ }^{22,23}$ gold nanoparticles with a diameter below $2 \mathrm{~nm}$ have, however, been previously reported.

The TEM images also show that the chirally coated particles are much smaller and show narrower size distribution than the hexanethiolate coated particles (Figures 1 and 2).
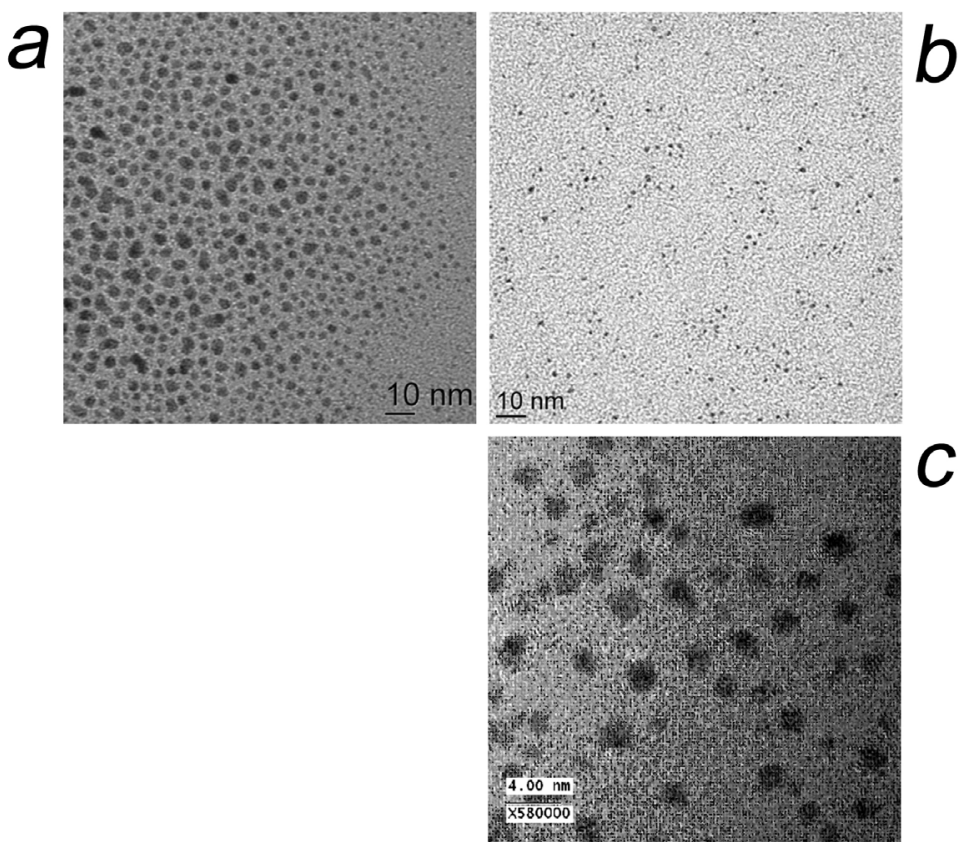

Figure 1. Low (a, b) and high resolution (c) transmission electron micrographs showing the relatively monodisperse size distributions of the gold nanoparticles. a) Hexanethiol passivated particles 1, b) particles matured with chiral ligand 2, c) HRTEM image of the TEM images of particles 2 .

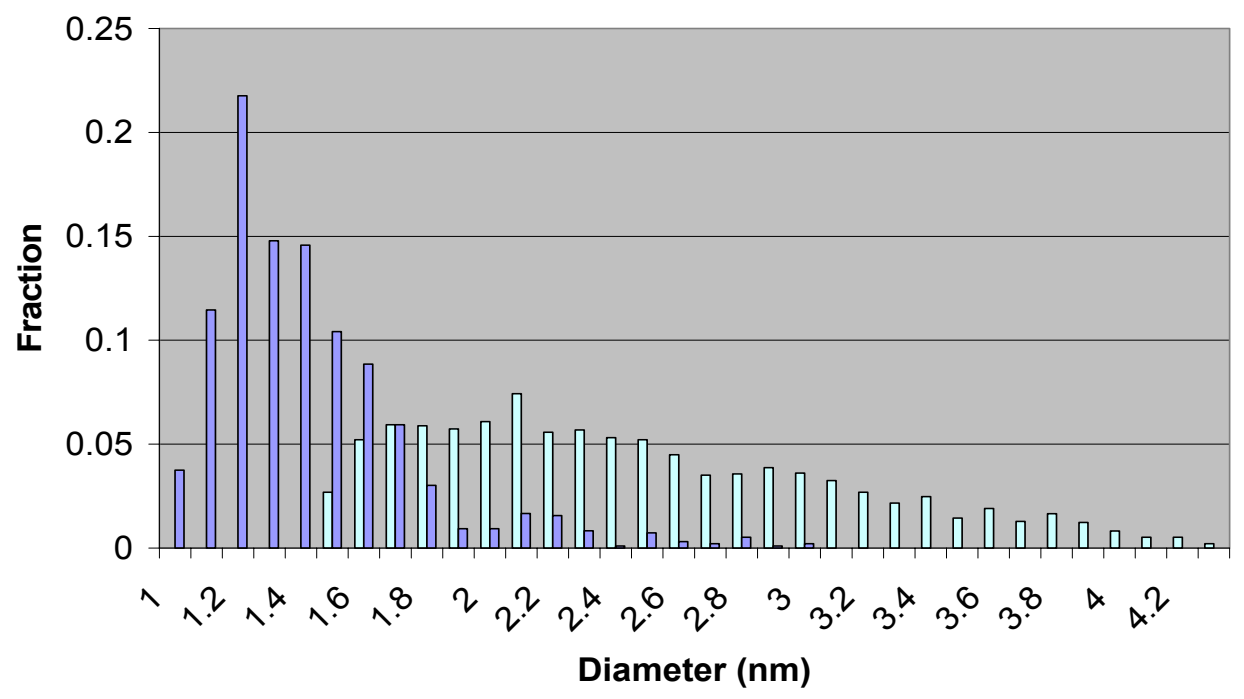

Figure 2. Size distribution of particles 1 (light blue, 1937 particles) and 2 (dark blue, 986 particles). 


\section{Catalytic activity}

The chiral AuNP 2 was tested for catalytic activity. The test reaction used was the alkylation of chalconol acetate 3 with dimethyl malonate (Scheme 2). The catalyst was prepared by complexing 6 mol- $\%$ of ligand 2 and 2 mol- $\%$ of allylpalladium chloride at elevated temperature $\left(50^{\circ} \mathrm{C}\right)$. To the cooled $\left(-78^{\circ} \mathrm{C}\right)$ solution were added ester 3 , dimethyl malonate and the bases, and the reaction was carried out first at room temperature $(30 \mathrm{~h})$ and then at $40^{\circ} \mathrm{C}(16 \mathrm{~h})$. Enantioselectivities were recorded using chiral HPLC and the evaluation of the stereochemistry was based on earlier literature studies. ${ }^{24}$

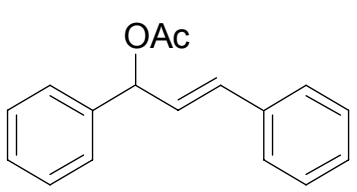

rac-3

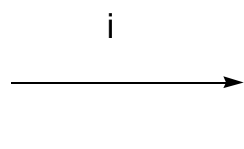

i. AuNP 2, Dimethyl malonate, BTMSA, AcOK, [allylPdCl $]_{2}, \mathrm{THF}$.

Scheme 2. Asymmetric alkylation.

In order to evaluate the catalyst efficiency of $\mathbf{2}$, the test reaction was performed with both polymer-supported and soluble PyOX-ligands 5 and 6-7, respectively, with an ester functionality at the 5-position of the pyridine ring. (Figure 3) The reaction was also tested with the Moberg ligand $\mathbf{8}{ }^{24}$ From this test series (Table 1) one can conclude that benzyl substituted oxazolines give lower selectivities as compared to $\mathbf{7}$ and $\mathbf{8}$; electron withdrawing substituent at the 5position of the pyridine ring is not responsible for a lower enantioselectivity; and most importantly for this study, the AuNP catalyst 2 a selectivity better than a tradition polystyrene bound catalyst (entries 1 and 2).
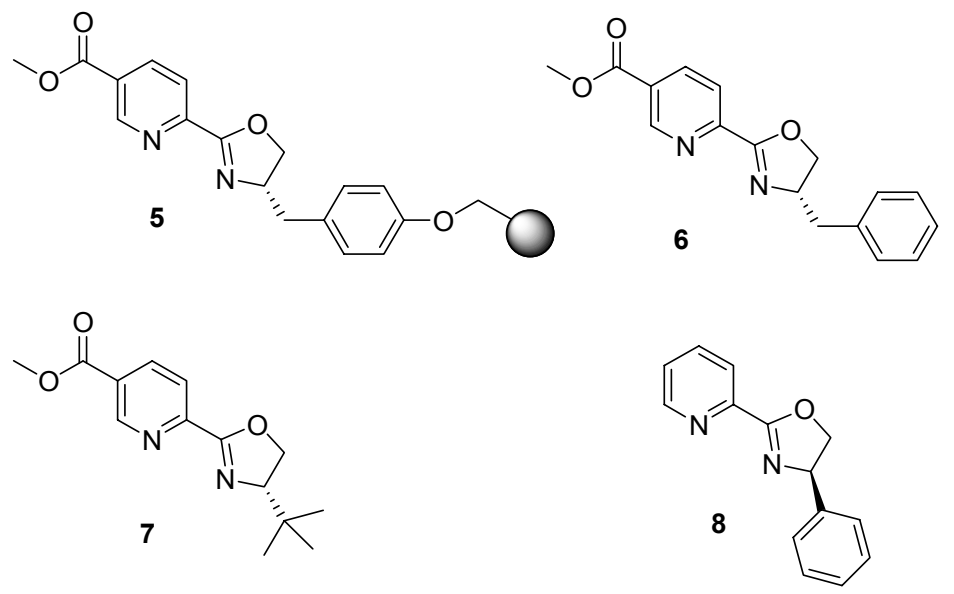

Figure 3. Model ligands (5-8). 
Table 1. Enantioselectivity and yield of ligand $\mathbf{2}$ in comparison with different analogues

\begin{tabular}{c|ccc}
\hline Entry & Ligand \# & Conversion (\%) & ee (\%) \\
\hline 1 & $\mathbf{2}$ & 5 & $13(S)$ \\
2 & $\mathbf{5}$ & 74 & $7(S)$ \\
3 & $\mathbf{6}$ & 100 & $20(S)$ \\
4 & $\mathbf{7}$ & 100 & $73(S)$ \\
5 & $\mathbf{8}$ & 100 & $48(R)$ \\
\hline
\end{tabular}

In conclusion, we have prepared a novel nanoparticle of a size never experimentally achieved before. Nanoparticles of this size have been predicted to be hollow, as supported also by our experimental analysis (CHN, ESCA, TEM). The PyOX-ligands surrounding the core are known to be effective ligands in asymmetric synthesis, thus allowing the construction of chiral organometallic catalysts on gold nanoparticles. This feature is demonstrated by using the novel particle 2 in a well-known catalytic reaction. Its selectivity is superior to its polymer-supported analogue and only somewhat poorer than that of the soluble benzyl analogue (6). A catalyst designed like 2 is, however, being pursued for applications in e.g. flow reactors for higher efficiency, a feature barely applicable for soluble catalysts.

\section{Experimental Section}

Preparation of Au nanoparticles 2. In a $25 \mathrm{~mL}$ round bottomed flask under an atmosphere of Ar, $30 \mathrm{mg}$ of particles 1 were dissolved in $5 \mathrm{~mL}$ toluene. The thiol ligand (33 $\mathrm{mg}, 96 \mu \mathrm{mol}$ ), prepared for this purpose $\mathrm{e}^{20}$, was dissolved in $1 \mathrm{~mL}$ toluene was added to the solution via syringe. After 25 days, particles 2 were precipitated by adding $6 \mathrm{~mL}$ absolute ethanol. The particles were filtered off using a Millipore $0.45 \mu \mathrm{m}$ filter, air dried and analyzed with CHN-analysis and ESCA analysis. The size of the gold core was determined using TEM microscopy. CHN C 40.76 $\mathrm{H} 3.58 \mathrm{~N} 3.87$, giving the approximate ratio $\mathrm{Au}: \mathrm{S}: \mathrm{N}=1: 1: 1$ calculated from compounds 1 and $2{ }^{21}$ This gives the ratio between hexanethiolates and the active ligand sites as $1: 1$ (two nitrogen atoms on the active ligand and none on the hexanethiolate).

Asymmetric catalytic synthesis of 4. General procedure. ${ }^{24}$ In a Schlenk apparatus, $5.4 \mathrm{mg}$ $(5.0 \mu \mathrm{mol}$ of ligand sites, $6 \mathrm{~mol}-\%)$ of ligand 2 was suspended in $3 \mathrm{ml}$ THF $\left(\mathrm{CH}_{2} \mathrm{Cl}_{2}\right.$ for soluble and polymer supported ligands). To this solution was added $0.65 \mathrm{mg}$ allylpalladium chloride dimer $(1.8 \mu \mathrm{mol}, 2 \mathrm{~mol}-\%) / 0.30 \mathrm{ml}$ THF. The mixture was cooled to $-78^{\circ} \mathrm{C}$ and degassed with Ar for 15 minutes. After this, the solution was heated on a $50^{\circ} \mathrm{C}$ bath for $3 \mathrm{~h}$. After this, it was cooled again to $-78^{\circ} \mathrm{C}$ and $22 \mathrm{mg}(87 \mu \mathrm{mol}, 100 \mathrm{~mol}-\%)$ of racemic 3 in $1 \mathrm{ml} \mathrm{THF}$ was added, followed by $20 \mu \mathrm{l}$ (23 mg, $180 \mu \mathrm{mol}, 200 \mathrm{~mol}-\%)$ of dimethyl malonate, $65 \mu 1$ (53 mg, $260 \mu \mathrm{mol}$, $200 \mathrm{~mol}-\%)$ of N, O-bis-trimethylsilylacetamide and $2 \mathrm{mg}(20 \mu \mathrm{mol}, 20 \mathrm{~mol}-\%)$ potassium acetate were added, followed by degassing with Ar. The mixture was lifted to ambient 
temperature. The reaction was followed by TLC, in the case of ligand 2 , it was heated to $40^{\circ} \mathrm{C}$ overnight. Selectivity and yield of the product were determined by chiral HPLC (Chiralpak AD, $10 \% \mathrm{iPrOH} /$ hexane, $0.5 \mathrm{ml} / \mathrm{min}, \mathrm{t}_{\mathrm{R}}\left((S)-\mathbf{4}=27.1 \mathrm{~min}, \mathrm{t}_{\mathrm{R}}((R)-\mathbf{4}=33.9 \mathrm{~min})\right.$. NMR-data of 4 was identical to that of Moberg. ${ }^{24}$

\section{Acknowledgements}

The authors would like to thank Dr. Jan Tois (HUT, Laboratory of Organic Chemistry) for his contribution to the synthesis of soluble ligands, Dr. Leena-Sisko Johansson (HUT Analysis Centre) for ESCA analysis and Mr. Timo Laaksonen (HUT, Laboratory of Physical Chemistry) for TEM images. This research was supported by the National Technology Agency of Finland TEKES and the Emil Aaltonen Foundation.

\section{References and Footnotes}

1. Daniel, M.-C.; Astruc, D. Chem. Rev. 2004, 104, 293.

2. Alivisatos, A. P. Science 1996, 271, 933.

3. Benaglia, M.; Puglisi, A.; Cozzi, F. Chem. Rev. 2003, 103, 3401.

4. Schmid, G.; Pfeil, R.; Boese, R; Bandermann, F.; Meyer, S.; Calis, G. H. M.; van der Velden, J. W. A. Chem. Ber. 1981, 114, 3634.

5. Brust, M.; Walker, M.; Bethell, D.; Schiffrin, D. J.; Whyman, R.J. Chem.Commun. 1994, 801.

6. Ackerson, C. J.; Jadzinsky, P. D.; Kornberg, R. D. J. Am. Chem. Soc. 2005, 127, 6550.

7. Templeton, A. C.; Wuelfing, W. P.; Murray, R.W. Acc. Chem. Res. 2000, 33, 27.

8. Santhanam, V.; Liu, J.; Agarwal, R.; Andres, R. P. Langmuir 2003, 19, 7881.

9. Hiramatsu, H.; Osterloh, F. E. Chem. Mater. 2004, 16, 2509.

10. Itoh, H.; Naka, K.; Chujo, Y. J. Am. Chem. Soc. 2004, 126, 3026.

11. Pal, U.; Sanchez Ramirez, J. F.; Liu, H. B.; Medina, A.; Ascencio, J. A. Appl. Phys. A 2004, A79, 79.

12. Lu, Z.; Prouty, M. D.; Guo, Z.; Golub, V. O.; Kumar, C. S. S. R.; Lvov, Yu. M. Langmuir 2005, 21, 2042.

13. Harpeness, R.; Gedanken, A. Langmuir 2004, 20, 3431.

14. Ascencio, J. A.; Mejia, Y.; Liu, H. B.; Angeles, C.; Canizal, G. Langmuir 2003, 19, 5882.

15. Kell, A. J.; Donkers, R. L.; Workentin, M. S. Langmuir 2005, $21,735$.

16. Tsunoyama, H.; Sakurai, H.; Ichikuni, N.; Negishi, Y.; Tsukuda, T. Langmuir 2004, 20, 11293.

17. Ozkan, M. Drug Discovery Today 2004, 9, 1065 and references cited therein.

18. Tamura, M.; Fujihara, H. J. Am. Chem. Soc. 2003, 125, 15742. 
19. Johansson, M. P.; Sundholm, D.; Vaara, J. Angew. Chem. Int. Ed. Engl. 2004, 43, 2678.

20. Oila, M. J.; Tois, J. E.; Koskinen, A. M. P. Tetrahedron Lett. 2005, 46, 967.

21. Determination of the $\mathrm{S}: \mathrm{Au}$ - ratio: The $\mathrm{CHN}$-data on compound 1 reveals the ratio between carbon and hydrogen $\left(\mathrm{n}_{\mathrm{C}}: \mathrm{n}_{\mathrm{H}}=1: 2\right)$, showing the absence of impurities. The ratio $\mathrm{n}_{\mathrm{S}}: \mathrm{n}_{\mathrm{C}}=$ $1: 6$ (Figure 1), giving $\mathrm{n}_{\mathrm{S}}=0.36$ and the relative mass fraction of sulphur can be calculated $\left(\mathrm{w}_{\mathrm{S}}=11.76\right)$. As the rest of the compound is the gold core, the mass fraction of gold is $\mathrm{w}_{\mathrm{Au}}$ $=57.36$, giving $\mathrm{n}_{\mathrm{Au}}=0.30$. Considering inaccuracies, this gives $\mathrm{n}_{\mathrm{S}}=\mathrm{n}_{\mathrm{Au}}$. Calculating for compound 2 , we assume $\mathrm{n}_{\mathrm{N}}: \mathrm{n}_{\text {act.ligand }}=2$. As the ratio $\mathrm{n}_{\text {Nactive }}: \mathrm{n}_{\text {Cactive }}=1: 9$ and the carbon ratio between ligands is $\mathrm{n}_{\text {Cactive }}: \mathrm{n}_{\text {Chexthiolate }}=18: 6=3$, we get the ratio between ligands (from the total amount of carbon in $\mathrm{CHN}$ of 2 ) as $\mathrm{n}_{\text {active }}: \mathrm{n}_{\text {hexthiol }} \approx 1: 1$. As the total amount of sulphur = total amount of ligands, we can calculate the mass fraction of sulphur $\left(\mathrm{w}_{\mathrm{S}}=\right.$ 8.98), giving the residual mass fraction as $\mathrm{w}_{\mathrm{Au}}=42.81$, giving the approximate ratio of $\mathrm{n}_{\mathrm{N}}$ : $\mathrm{n}_{\mathrm{S}}: \mathrm{n}_{\mathrm{Au}} \approx 1: 1: 1$ for ligand 2 .

22. Meier, D. C. and Goodman, D. W. J. Am. Chem. Soc. 2004, 126, 1892.

23. Chen, M. S.; Goodman, D. W. Science 2004, 306, 252.

24. Nordström, K.; Macedo, E.; Moberg, C. J. Org. Chem. 1997, 62, 1604. 